\title{
Unschooling Motherhood: Caring and belonging in mothers' time-space
}

\author{
Nadia von Benzon
}

Lancaster Environment Centre, Lancaster University, Lancaster, UK.

n.r.vonbenzon@lancaster.ac.uk

Nadia von Benzon is a lecturer in Human Geography at Lancaster University. Her work focuses on social and cultural geography with a particular interest in children, youth and motherhood in both contemporary and historical contexts. 


\section{Unschooling Motherhood: Caring and belonging in mothers' time-space}

For mothers, time is experienced in unique patterns reflecting mother-child relationships shaped by caring responsibilities and producing notions of belonging. The temporal and spatial rhythms of mothers' lives are determined by interembodiment and co-presence; particularly apparent when offspring are infants and incapable of independent mobility and self-care. Formost mothers theserhythms evolve as children grow and develop, with a particular increase in independence experienced by many mothers when their children reach school age. However, for home educating mothers, the constant interembodiment and co-presence of the mother-child relationship extends into late childhood resulting in alternative habitus to mothers who attend to school and to work. This paper draws on blogs authored by unschooling mothers in the UK, Australia and the USA - mothers whose children engage in a child-led form of home education - to explore a geography ofmotherhood that contrasts with the mainstream experiences that determine socio-cultural and policy-generating expectations. In so doing, this paper contributes to geographical discourse concerning the way in which motherhood impacts on experiences of time and space whilst also challenging mainstream representations of motherhood and particularly the widespread problematisation of caring. This paper demonstrates the way that caring relationships embed an individual in complex reciprocal networks leading to a particular identity-in-space which in turn influences, and is influenced by, temporal rhythms.

Keywords: Motherhood, time, habitus, interembodiment, unschooling, social media

\section{Preface: Covid-19 and home education}

This paper was written and reviewed prior to the international outbreak of Covid-19 and the ensuing lockdown and resultant closure of schools and childcare facilities that occurred internationally. As I attend to the final edits of this paper, my own children join millions of others worldwide reluctantly learning from home, as I become an equally reluctant full time home learning facilitator (alongside being a full time academic). I am careful, at this stage, to avoid drawing overt parallels between the reflections and findings in this paper, and the crisis 
in which we currently find ourselves. The experience of the mothers described in this paper, who have chosen to home educate, or who home educate against the mainstream out of necessity, should not be compared to, or subsumed within a widespread experience of enforced home learning as a result of a pandemic. I do hope to be able to expand more on my own lived experience of facilitating home learning, elsewhere, when I have time and space to reflect (until then, you get some insight into my experience through a very short blog article: http://tiny.cc/c71goz).

What does appear certain, nine weeks in to UK-wide 'lockdown', is the vastly uneven and gendered nature of the burden of childcare and home educating in a period in which there are no out-of-home childcare options available for the majority of families. The international press, drawing on anecdote and exploratory research, is already clear that it is mothers who are bearing the brunt of the burden of childcare (Hinsliff 2020; Lewis 2020; Scharff 2020). Of course, the situation is most dire for single mothers, over-represented amongst those undertaking poorly paid, precarious, work outside the home (Oppenheim 2020). However, the inequality is also occurring both in households where women are giving up their own work to care for the children to prioritise their partner's higher salaried job, and in households where women continue to work but in addition take on the majority of childcare, oversight of home education, and broader household duties (Medina and Lerer 2020). My own personal experience is one in which the virus' own sex bias has compounded any underlying socio-economic asymmetry, resulting in an ill husband who is physically incapable of doing his share of childcare and domestic labour.

Thus the paper that follows, whilst holding no direct relation to the experience of mothers facilitating home learning as a result of COVID-19, has clear potential relevance to future research on this topic. Particularly this relevance lies in a focus on the gendered experience of domestic time-space in families where children are not attending school.

\section{Introduction}

This paper seeks to explore belonging, as relationships of care, through the lenses of time and rhythm. The argument will build on theories of women's experiences of time to explore the unique temporal lifeworlds of unschooling mothers - mothers whose children engage in a 
child-led form of home education. This exploration draws on empirical research undertaken using blogs written by unschooling mothers. For these authors, life presents in unique rhythms that are not as closely, or perhaps as obviously, tied to social structures and institutions as mothers who attend to school and to labour in the formal economy. The blogs provide windows into the intimate and emotional experiences of their authors. As such they offer fascinating insight into the complex and intricate relationships between mothers, time, mobility and belonging, presenting an alternative perspective on motherhood. This paper seeks to demonstrate the unique habitus of mother and child experienced in a relationship of prolonged interembodiment and co-presence.

Interrogating blog posts allows for an exploration of motherhood as identity, practice and performance (Luzia 2010; Aitken 2000), and ultimately as a process of belonging. Bennett (2015) argues that to belong is an ongoing experience, in which everyday activities, particularly those involving 'care', build relationships between people, weaving an individual into a complex network of reciprocal exchanges of resources and emotion. In the case of motherhood, weaving develops intimate bonds between mother and children, and between mother and their own 'caregivers', including partners, parents, friendships and broader social networks. This notion of belonging, as connections of care between oneself and others, is understood to be fundamental to both our individual identities and the way in which we relate to others and conceptualise the material space we inhabit (Lewis 2017). Antonsich (2010) describes belonging as being two distinct things: as a feeling of being 'at home' or 'placebelonging-ness' and as discourse that includes and excludes or a 'politics of belonging'. However, this paper explores belonging in a manner, akin to Mee (2009), as process and as performance. Here, blogging is seen as an act of belonging. An act stemming from a knowledge that unschooling mothers do, or could, belong, whilst reflecting a desire to belong better.

The boundary of the group(s) to which mothers perceive themselves as belonging, or seek to belong, changes in different contexts and over time (Wright 2015) so that, even for one individual, there is no single identity or singular notion of belonging (Gilmartin and Migge 2016). These blogs are explored as a mechanism of belonging to a 'home education' or specifically 'unschooling' community and as a way of extending this community by reaching out to potential members. However, they are also explored as a means of demonstrating belonging within the local community and of illustrating author's cooperation or normalcy within a place-based construct of locality. This paper seeks to demonstrate the way that caring 
relationships forged, developed or performed online, produce a sense of identity-in-place or a notion of self as intertwined with others and the local environment, which in turn, influences individuals' use of time within and beyond the home. The complex geographical literatures addressing time, caring and belonging are explored as the paper unfolds. However, the following section briefly presents an overview of relevant literature on: mothers, caring and families; blogging; and home education. This provides important foregrounding to the empirical data drawn on latterly.

\section{Exploring motherhood}

\subsection{Motherhood, care-giving and interembodiment}

In recent decades, 'care' has been foregrounded in geographical research (Conradson 2010). Care has been rigorously explored in relation to health and therapeutic environments (Parr and Philo 2010), old age, disability and death (Milligan et al. 2016; Carlsson et al. 2020), policy landscapes (Lancione 2014), domestic settings and childcare duties (Barker 2011). This discourse has charted a nineteenth century institutionalisation of care, and a (very) late twentieth century redomestication of care, resulting in a complex 'blurring of boundaries' of care between state or institution and home (Milligan 2000). In terms of both health and social care and domestic and childcare duties, focus has been drawn to women's experiences and the everyday (Kallio and Hakli 2019; Tarrant and Hall 2019). Thus care is acknowledged as being mundane, gendered, and undisputedly fundamental to theorising about society, particularly in relation to caring for children (Dyck 1990). Whilst fathers' roles in caring for children have increased significantly in recent decades, mothers continue to take more of the caring load (Damaske 2013; Frohlick 2006). This gender division is posited to begin in early infancy with fathers avoiding 'difficult' tasks in infant care, laying the foundations of ongoing gender divisions in child-related care labour (O’Brien 2007; Rose et al. 2015). In the Anglo-AmericanAustralian parenting paradigm, the 'good' mother is intimately engaged with the everyday minutiae of their children's lives (Damaske 2013), infinitely emotionally and physically available to her children and spouse, placing their needs above her own (Choi et al. 2005; Parker and Morrow 2017). 
This position as primary caregiver is underpinned by the assumed interembodied, interrelational and intercorporeal (Merleau-Ponty 1968) biology of procreation, pregnancy and birth, and infant care (Holt 2017; Lane 2014). Whittle (2018) and Boyer and Spinney (2016) explore the way in which infants impact on parents', particularly mothers', mobility through their inability to propel themselves efficiently and safely through space. As such, infants become interembodied with their care-giver, reliant on the other's body for their personal mobility (Lupton 2013). This notion of interembodiment might also relate to an infant's need for physical contact with caregivers, for comfort and reassurance (Tahhan 2013), and to the bodily interconnection that might be experienced should a mother breastfeed her child (Holt 2017). This mother-child interconnection is then socially understood as not just influencing but radically altering the mother's identity through the way in which the identity of a newborn baby, as both pure and malleable (Lupton 2013), is socially extrapolated to influence the perception of 'good motherhood' as a state that is 'natural' and undefiled. Accordingly, the status of 'mother' is embedded within particular expectations of behaviour and practice in relation to offspring, co-parents, wider kinship networks, and the broader community.

These interrelationships and interembodiments have been theorised through feminist scholarship that presents the mother and baby as an integrated unit. In this discourse the baby is positioned as 'human becoming' (Balen et al. 2006; Uprichard 2008), lacking the necessary agency to interact independently with the world around them (Holt 2017). This is not to say that babies are devoid of agency, as new mothers undergo a revolution of life experience as a result of the need to attend to their baby. Thus babies can be positioned in being agentic in the way in which they can control the actions and behaviours of their care givers. Geographical approaches to the mother-child relationship demonstrate however that interembodiment is not a closed system relationship of symbioses between two bodies (or of a parasitic child-mother relationship). Rather it is a relationship that is profoundly shaped, ordered and processed through interaction with the material and social world around them (Lupton 2013; Bennett 2009; Clement and Waitt 2017).

Typically developing babies and young children become less interembodied as they are weaned (if indeed they were breastfed), become mobile and articulate, and develop agency around personal care. As such, the material, human and non-human phenomena that contribute to the child's life will change, with the loci of agency constantly in motion. For most, the intensity of the interembodied and co-present mother-child relationship will diminish as the 
child gains autonomy, and the range of actors directly influencing the child grows. Indeed, the phenomena influencing the child's lived experience, which might range from issues of food to children's toys, obesity politics to childcare and education, healthcare to holidays (Evans 2009; Holloway and Pimlott-Wilson 2014; Horton 2018; Hall and Holdsworth 2016 amongst many others), are potentially infinite in number, and undoubtedly beyond the scope of this paper. Whilst mother and child will develop increasing body autonomy, the mother remains primarily responsible for meeting the child's basic care needs, of food, shelter, emotional support, as well as education and health care, throughout the offspring's childhood and for many, into early adulthood.

\subsection{Mothers in Space-Time}

Hagerstrand (1985), in his seminal work on time-geography, argued for the importance of understanding people within landscape, or place, based on the temporality of their relationship to the place. According to Hagerstrand, the social framework in which we inhabit places is as much a product of the moment as it is the space. That is to say that relationships, networks and agency are all entirely dynamic, and our experience of place, and our relationship to place, are built on a complicated patchwork of time-sensitive contributors. Hagerstrand's approach to space encourages an emphasis on the temporality or the potential flightiness, of our emotions in place at any given moment. Building on Lefebvre's rhythm analysis (Lefebvre 2004) which problematises repetitive and subconscious actions as reflective of social structure, many geographers have called for the need to interrogate time, routines and the messy complexity of the interplay between time and space. Edensor (2006) for example, demonstrates the way that everyday routines reflect broad underpinning notions of identity such as nationalism. Bourdieu's notion of habitus, which has significant influence in social and cultural geography, particularly concerning education (Holton 2015; Holt, Bowlby and Lea 2013; Pimlott-Wilson 2011), presents a specific approach to situating identity within time. Habitus posits identity as a form of belonging with a distinct temporality that reflects complex networks of culture and social structures as unique to each person. Habitus is therefore dependent not only on one's own personal narrative, or history, but also an individual's place in a broader time structure.

In the last 25 years geographers have built on Hagerstrand's original work on the importance of time through feminist geographers' interventions in the discourse (Rose 1993). 
Davies (2001) argues that time does not apply equally to all. Some people are more in control of time, having more access to time as a resource, than others, an idea referred to by Nockolds (2016) as 'men's' time' versus 'women's time' or 'clock time' and 'caring time'. Davies (2001) follows Lefebvre and Bourdieu in critiquing the traditional notion of time as quantifiable and linear. Whilst Lefebvre and Bourdieu present time as universally non-structured, complex and interacting with space, Davies argues that this messiness is not evenly experienced. Davies discusses the way in which women may experience time concurrently as women undertake multiple activities, or roles, at once. As such, Davies argues that time is laden with influences of power and control, and notions of gender and time, and particularly women's diminished control over time, are particularly prescient. This lack of control over time is identified in research acknowledging mothers, and particularly mothers of young children, as chronically 'time poor', due to the time required to provide basic care of an infant and the household, in addition to the pressures to undertake other tasks associated with being a 'good mother' (Gunthorpe and Lyons 2004).

Notions such as 'time poor' and the idea of caring roles as generating a new time-space of 'women's' or 'caring' time, serve to problematize the inter-connectedness between mother and child. Through this rhetoric, men's time is normalised, and alternatives to a capitalist and clock-driven routine risk being positioned as lesser-than and less-desirable. In confronting the differential in control that men and women have over their experience of using time, or living in time, as a result of differentiated caring roles, it is easy to overlook the alternative experiences of relationality and belonging that might be facilitated through 'caring time' rather than 'clock time'. The remainder of this paper will go on to explore the ways in which unschooling mothers approach belonging as a process, and a performance (Mee 2009) through the authorship of public blogs.

\section{Unschooling Blogs}

\subsection{Blogs as care phenomena}

Lupton (2013) identifies good parenting as a performance. In contemporary society, this performance does not only extend to the social network of community, family and friends, but rather indefinitely into cyberspace (Chae 2017a). Mothers are amongst the most frequent users 
of online social spaces, with high levels of engagement with social media and blogging platforms (McDaniel at al. 2012). Whilst a range of motivations for social engagement online have been identified, the development of social networks for support, information seeking and entertainment are key (Jang and Dworkin 2014; McDaniel et al. 2012). Social media engagement develops existing friendships based on in-person relationships, and creates new alliances - both on and offline (Doty and Dworkin 2013; Gilmartin and Miggie, 2016). In addition to these motivations for social media engagement, blogging has been associated with desires to express oneself and to record keep (Jolly and Matthews 2017). The widespread popularity of social media as a space for building parenting relationships is attributed to the erosion of traditional family networks and a loss of familial and local sources of advice and support (Johnson 2015).

Research suggests that blogging, and broader social media engagement, might be envisaged in complex ways in relation to care work. A number of studies have demonstrated the way in which mothers engage online as a way of supporting the care of their own children through searching for advice related to health, nurturing and developmental issues (Johnson 2015). They may also use the internet as a way of subverting narratives of good motherhood complaining about their families and domestic duties, parodying their lives, and celebrating non-conformity (Pederson and Smithson 2013). By contributing to these conversations, with both practical and emotional support, mothers provide care for each other and by extension, others' families (Madge and O'Connor, 2006). Through this practice, reciprocal care relationships develop online as women build networks of support, creating an identity of belonging in different virtual settings (Jang and Dworkin 2014). Mothers may also connect online when they are subverting broader social norms, in order to find alternative spaces of belonging. One such example is home education blogs (Jolly and Matthews 2017; von Benzon 2019a).

\subsection{Unschooling}

Home education is the practice of educating children away from the mainstream State and independent education system. In the UK (as well as the US and Australia), home education is legal, provided children's learning is facilitated at an 'appropriate' level. There are infinite ways of 'doing' home education, largely closely tied to family motivations for home educating. The 
binary (and USA-focused) distinction presented in the literature is a 'Heaven' and 'Earth' dichotomy (Stevens 2001). Stevens' theory posits that parents home educate either for religious reasons - believing the mainstream school system is too liberal - or due to social or environmental justice reasons - believing it is too conservative or authoritarian. These approaches have in common the belief that there are entrenched failures in the school system. Therefore both the 'heaven' and 'earth' justifications for home education can be interpreted as activism, thus representing a social movement (Collom and Mitchell 2005). By contrast, parents may have reasons to home educate which relate to their own child's capacity to learn alongside a mainstream class, or within a mainstream school environment (Parsons and Lewis 2010). This particularly happens where children have an impairment or disorder, experience bullying, or are perceived as exceptionally gifted (Kendall and Taylor 2016).

Many home educating families will support their children's education through the use of curricula. However, 'unschoolers' practice autonomous education following their own interests to identify topics and skills that they then research themselves (Petrovic and Rolstad 2016; Gray and Riley 2013). The parent becomes a facilitator, rather than an educator, and allows the child complete agency in their learning. This approach to home education is based on the philosophy that children are naturally inquisitive and allowing children freedom to learn as they wish in childhood lays the ground for a life-long love of learning (Holt 1976; Dodd 2009). Whilst geographers are now engaging vociferously with education, and beginning to address home education (Kraftl 2012; Kraftl 2016), there is yet to be any geographical engagement with unschooling as an entirely unstructured form of home education. Unschooling may be of particular interest to geographers as a practice that ostensibly operates outwith fixed boundaries of time and space at once presenting an everyday activism as parents seek to do differently, whilst also presenting a performance of intensive mothering (Parker and Morrow 2017).

\section{Method}

The empirical data used throughout this paper was purposively sampled from 14 home education blogs. The blogs all addressed 'unschooling' and were written in English, originating from the UK, Australia and the USA. The blogs were identified using an iterative approach in which a combination of search engines and links were used to uncover these niche blogs. The 
initial scope of the project was to explore the experiences of unschooling families, but the realisation that each of the fourteen blogs was authored by a person identifying as a mother, led to the specific focus of this paper. Analysis of blogs was thematic, reflexive and iterative, undertaken using Nvivo8. Following others engaged in the qualitative analysis of blogs (Dahlen 2013), this involved the close reading of the blogs to identify codes which were developed as more blog posts were included. Once a first read through of the blogs was complete, with an initial coding system, all blogs were then returned to for a more nuanced application of the codes to the text, and refining of the coding system itself. The approach, and thus I hope the outcome of the paper, intended to sit comfortably alongside a material feminist agenda (Lupton 2018), exploring the complex identity experience of women alongside their intraembodied and co-present children as the centre-point in a complex network of relationships and experiences-in-place (Warin 2015; Mackay 2019). The approach was implicitly intersectional in that it foregrounded a minority experience of motherhood, overlooked in public policy and rhetoric addressing the lived experience of mothers. However, the demographics of participants - as mostly white, heterosexual and living with a male partner- reflect the broader demographic of blogging mothers as white, married and heterosexual (Orton-Johnson 2017) which in turn also reflects the broader demographic of home educating families as white households with two parents (CRHE, 2020).

There are a myriad of ethical and practical challenges associated with the use of blogs as research data, and in-depth discussion of these issues goes beyond the scope of this paper. These issues are expanded upon in more detail elsewhere, relating specifically to this project (von Benzon 2019b), and to other projects (Madge 2007). In these reflections on the ethics of using blogs, key concerns include: the rights of the researcher to use publicly-accessible online data and the rights of the blog author to acknowledgement versus confidentiality. This project received ethical approval from Plymouth University to follow a 'covert' approach, common in internet-based research (Pederson 2014). That is to say that authors were not informed of their 'participation' in the research on the basis that: i) their writing was publicly accessible without the need for the researcher to register or achieve membership of any group; ii) the author did not interact with the participants (i.e. did not leave comments or otherwise contact blog authors), and remained as a 'lurker' (someone who visits discussion forums to read content but does not interact in the space) and iii) blog authors remained non-identifiable through the avoidance of direct quotations and changing of names and other identifying details. All 'quotes' 
used within this paper are in fact paraphrasing the original authors and therefore the authors are not easily traceable through internet search engines.

The benefit of this methodological approach is that, as with other sorts of secondary data, the data presented is arguably 'naturalistic'. Firstly, it has not been created for the purpose of the research, and the data should therefore not reflect the perceived objectives of the research. Secondly, the researcher is not involved in the initial generation of the research data. On the other hand, it is important to recognise the blog posts as performative, with mothers presenting their experiences in a particular manner to develop a specific identity and appeal to their intended audience (Bartholomew 2012; Jane and Dworkin 2014; Dawson 2016).

\section{Time-space and identify formation through unschooling}

\subsection{The time-cost of unschooling for mothers}

The blogs reflect multiple ways in which home educating mothers experience lack of control over time, or time poverty (Davies 2001), and vastly conflicting demands on their time due to their lack of independence from their children. Indeed, for many of the women, their daily life experiences appear to reflect Nockolds' (2016) distinction between 'men's time' as independent, and 'women's time' as interdependent and relational. Similarly, focusing on mothers who are mountaineers, Frohlick (2006) explores the notion of masculinity as a prerequisite for being able to leave familial responsibilities and domesticity and to spend time away from home life. For each blog author, home education is an activity that is done largely, if not solely, as the single adult in-charge. In one case, this is a single-parent household, but primarily, this reflects the fact that the male adult works outside the home whilst the female adult remains responsible for the children and their education. It is important to note here that I recognise that a portrayal of families as units with one male and one female adult is highly heteronormative and risks the further marginalisation of alternative familial structures. However, I could not find any unschooling blogs that were authored by adults identifying as part of same-sex or non-binary family units (although one blog was authored by a single parent). 
Simone: the problem of developing my own business from home is that I just have to 'struggle' and 'juggle' to fit yet more into the day.

Lucy: We do a variety of groups, activities and classes, I need to fit in my own work, as well as find 'time for living'.

Tara: Sometimes I feel like I'm attempting to do 'three full time jobs' at the same time, and failing at all of them. [Tara goes on to discuss the way in which she sometimes sees her life as 'spinning plates'].

Connie: I have four children who are at home all the time. My youngest appears not to need sleep and my husband works and studies. I don't have any support with childcare or help around the house. I'm one person. I have to be Mum, spouse, teacher, nanny, writer, cook and taxi service. No doubt a 'zillion' additional things too. That's all before I can just be ME.

These extracts suggest that the business, and the busyness of caring for children and overseeing their education, makes unschooling mothers time poor and out-of-control over the way in which they spend their time (Davies 2001). Thus it is not Dyck's rhythms of employment and school that dictate the mothers' activities throughout the day, but a 'messier' 'mish-mash' of responsibilities and requests. These narratives presented by the blog authors are stories of haste, over-work and a lack-of-time to develop any independent identity that is separate from an experience of interembodiment and co-presence with their children. These illustrations reflect experiences of care-in-time that are largely one-way, in which the author is providing care to both children and spouse, but is not receiving care. As such, this sense of lack of time, narrated by blog authors, poses a threat to a sense of belonging, as restricted time results in a restriction over self-care activities including the formation of mutually-caring relationships (Bennett 2015).

On the other hand, Tara suggests that, rather than her children causing her time poverty, lack of time is posed by other, unspecified demands. This leads her to worry that she is not capable of sufficiently caring for and educating her children:

The night before term started round here, I threatened to send them back to school and that night, I cried. I felt like I wasn't enough. The beginning of September has felt rather 
overwhelming this year. Sometimes I feel I'm doing too much at once, not getting any of it right.

Thus despite the performance of the epitome of self-sacrifice and intensive co-presence, through home education, which Frohlick (2006) highlights as the socially accepted hallmarks of 'good mothering', unschooling mothers experience guilt at the insufficiency of the time they have to be physically and emotionally available to their children. Interestingly, we can also see evidence here of the hegemonic influence of the mainstream academic year. Tara acknowledges that it was 'the start of term' that led her to feel particularly under stress, despite the fact that her family were not formally bound by this routine. Nevertheless, this rhythm of 'the beginning of the school year' retains significance for Tara. Thus whilst unschooling mothers may have chosen to situate themselves and their children outside both the diurnal and the annual rhythms and repetitions of mainstream schooling - Dyck's (1990) reversible time, the structures of institutional time continue to exert control.

\subsection{Unschooling as time-gain}

Whilst the blogs clearly showed that unschooling mothers were time-poor (Nockolds 2016), and often experienced conflicting time demands from both the lack of routine, and the underlying social time structure, there was also a clear narrative of 'time liberation'. Dyck $(1990,471)$ describes paid employment and school organization as 'the parameters around which the scheduling of mothering activities needs to be organized'. The rhythms of mainstream schooling mothers' lives are not theirs to dictate as they organise daily life around school timetables. Considering Dyck's (1990) proposal of 'reversible time' - that is repetitive activity illustrated by Dyck as children going to and from school, or the adult to and from work - home schooling mothers living their everyday lives outside institutional timetables might be considered to have greater control over time. They are ostensibly able to shrug off schedules and routines, without specific responsibilities to be in particular locations at particular times. Their daily routines, the rhythm of their lives and therefore their habitus, is not controlled by external structures or state agency to the same extent as their working partners or their mainstream schooling peers. Some of the authors were clear that they were pleased to live beyond the constraints of 'clock time' and enjoyed living out-of-time. 
Sarah: Mornings are usually really 'relaxed'. This is a massive advantage over going to school. When I think back to how horrible I was in the mornings, when we had to have a school routine, I 'shudder'... I just feel so relieved that I don't have to meet anyone else's timetable these days

Sophie: Every morning I wake up feeling happy we decided to home educate. This is particularly the case now it's winter. Had we sent Charlotte to school our days would revolve around a horrible wet and cold school run twice a day.

Rhiannon: When we first started home schooling, my husband worked night shifts. When the kids were in school they barely saw him. Once we started home schooling, they got to spend so much more time with their Dad... 'We have found freedom'.

Time is also used, for many of the mothers, as a justification, or motivation, of the choice to unschool. The strongest claim here is that childhood goes too fast, with unschooling mothers seeking to maximise the time they are able to spend with their children - and therefore their caring opportunities, in a period viewed as particularly precious. As such, the emotional labour or ethics of care that are theorised as part of the emotional complexity of motherhood, are viewed positively by unschooling mothers. Kraftl (2016) found particularly that the perceived inability of school to cater to the bodily and behavioural needs of young children, without hastening their advance to adulthood, became a key reason for withdrawal of children from school. For example, Kraftl draws on an interview with a mother who was concerned that school was teaching her five-year-old child cursive handwriting, feeling this was too technical for her child's age and physical development. Thus mothers justify home education as a way of stalling time and allowing children to 'be children' without the pressure to grow up and rapidly develop, that they see from school.

Lizzie: Home schooling is so much more than not going out to school. People say 'won't your child miss out' but you could just as well say 'I'm so glad my child won't miss out by going to school'. I look at my kids playing outdoors with their friends, getting to enjoy freedom and the sunshine at the same time as learning, I know which makes more sense to me!

Jo: 'She's beginning to understand the way maths actually works, rather than just learning facts that don't seem to make any sense. As a result she doesn't fear maths like I did. 
This time-stalling - the prevention of the onset of adulthood - might also be seen as time-harnessing, in which mothers seek to retain the intensity of the mother-child co-present relationship experienced through the preschool years. In this way the mothers intend to retain a deep sense of caring as identity, in which mothers belong within their relationship to their children and home, and perhaps to a community or concept of motherhood.

Tara: Sending the kids to school would make life easier. But I'd also miss out. I'm not staying at home with the kids because I'm a 'martyr'.

For mothers in Kraftl's study, behavioural and bodily interventions seeking to push children towards adult behaviours and abilities were seen as part of a broader scheme in which the state sought to erode the bond between child and parents, moulding children as young citizens who were reliant on, and loyal to, the state and its institutions. Thus is was not just the physical separation of sending children to school that mothers feared, but also the emotional and ideological separation that would result from a broadening of the range of influences on their child's life. As such, the concept of caring as belonging here relates not just to a mother's sense of her own belonging within place and social relations, but their sense of their own child as belonging to them and to their family, rather than belonging to outside institutions or the state.

\subsection{The rhythm of unschooling}

Whilst happy to cast off the constraints of a normal school routine, and largely also those deriving from working in the formal economy, almost all of the blogging families chose to engage with some sorts of community activities that required routine and time management. Most of the families engaged with home education groups or other community-based classes, often in order to build routine but also resulting in a developed sense of belonging with-in a community, developing habitus that includes broader networks of relationships outside the home. There is a clear difference manifest between the perception of optional routines, offered by groups to which the family have chosen to belong, and enforced routines that Government, in its role of educator, may impose on children attending school. What is important here is perception of agency. The mothers are opposed to regulated time which is set and managed by the State, but are happy to participate in regulated time where they themselves approve the context. 
Felicity: Tuesdays tend to be 'unstructured' days, which actually doesn't work out very well. We really need something to go to in the morning, to tire out the little one so she'll have a nap.

Sarah: I never wanted our days to be structured, as I tend to be a 'chaotic' person. But we realized this year that we really need loose plans for each day.

As such, routine that is imposed and upheld by the mothers themselves, becomes a way to exert control more broadly over diurnal rhythms and thereby also over the management of domestic space, activity and the behaviours of children in the home. Perhaps in this way, the blogging mothers, whilst clearly experiencing 'caring time' are also able to feel a sense of 'clock time' or control over the way in which they are spending their day (Nockolds 2016). Whilst Sarah talks about setting out feeling that routine was not desirable, she found a structure to her use of time that is still able to reflect her identity (Edensor 2006) rather than subsuming her 'chaotic' personality. For Felicity, the use of a structure appears to pull apart the sense of overlapping time described by Davies (2001) in relation to mother's experience of simultaneously competing or sometimes compatible demands on their time.

\subsection{Blogs as time-marking}

The blogs themselves, are also a material reflection of mothers' time. Each blog represents women's labour as they take time to design and fill the blog with content. In some cases, the blog presents economic labour, as a source of income through advertising and product reviews or as a space to advertise goods for sale. However, for most of the women, the time taken to produce their blog is voluntary care work. The authors write as a way of building relationships and offering and receiving care through reciprocal channels of support and advice.

Lucy: Any questions? Please do feel free to ask away.

Felicity: Have you got any tips for activities to do outside with kids?

Maria: Here's where you might go for more information about home schooling, and information you can trust. 
The content of the blogs itself reflects messy and complex time. Each blog used chronology as one way of ordering posts (most blogs also attributed key words to each blog post, and it was therefore possible to isolate posts on a particular topic, but these were still presented chronologically), and blogs demonstrate periods of intense recording, as well as gaps in recording. For many of the mothers the act of blogging is regular, and built into a weekly or monthly rhythm. However, this rhythm is open to disruption. Sometimes the reader is enlightened as to the nature of the disruption, and at other times, the disruption remains unknown.

Carrie: Simon has been around a lot this week, so we've 'fallen out of a routine'.

Carrie: Recently Simon's been away once a week, my mother's been visiting for a while, and I'm so busy with the new baby, so things have been very easy going around here.

Lucy: We were definitely less' productive' for a few months after the baby was born. The kids watched a lot more television than I'd have liked.

Finally, the blogs also provide means through which home educating mothers justify their use of time. The blogs themselves offer descriptions of activities and sometimes of 'typical days', posts in which the authors' daily activities are laid out for scrutiny by the reader. Often this is implicit, although sometimes posts begin with claims such as 'I'm often asked what we do each day' or 'People are often intrigued about what a normal home schooling day looks like'. Authors such as Cheryl in Australia, Lauren in the USA, and Carrie, UK, use their blogs to provide a record that can be submitted to the authorities to evidence their home schooling activities. Here, performance of care and performance of time are interwoven as time becomes the space in which mothers need to demonstrate and justify the carework they provide. In so doing, the blog becomes the platform through which to present or even to perform time as having been spent in a worthwhile manner. The performance of habitus is complex here, as these different envisaged audiences define appropriate or worthwhile care differently. In other words, some blog visitors will look to promotion of the child's agency as appropriate care, whilst 'the authorities' will be looking to evidence appropriate educational and social engagements. 


\section{Conclusion}

Time is experienced uniquely by unschooling mothers. Following Kraftl (2013), unschooling was found to be a way for mothers to 'cheat' time, safeguarding childhood and preventing intervention by the state which might lead to an accelerated development of their child's independence. However, time also featured through rhythm. For many, there is an absence of enforced or structural rhythm in their lives. However, for most this absence is filled not by uninterrupted spontaneity, but by the adoption of routines. Whilst avoiding the staccato of work and school, the timetable organises the week, providing a steady pulse that serves to enrich the family's domestic life whilst simultaneously marking the passing of time. The paper demonstrates that temporality and caring are intertwined in the habitus of home educating mothers, resulting in a particular sense of belonging in which mothers feel intimately engaged with their own families and the virtual space and networks that they build through the creation and maintenance of their blogs. The lives of the blogging mothers illustrate a complex array of emotion, embodiment, materiality, socio-politics and relationships. Unschooling mothers' habitus reflects both universal experiences of motherhood such as infant interembodiment and experiences unique to women who are performing motherhood in a way that subverts the mainstream. Thus, we see that both the act and the performance of caring, and the intimate and embodied relationship between mother and child, determine the identity-in-place and thereby also the temporal rhythm of home educating mothers over an extended period of time. The blogs themselves represent a temporality that is deeply embedded in a rhetoric of care. These women belong to a virtual community which includes both other unschoolers, as well as imagined future unschoolers, and those with an interest in unschooling. The blogs therefore act as vessels for providing care to others, and for seeking out contact with a network hoped to reciprocate this care.

\section{Acknowledgements}

This paper is based on research that was undertaken during a temporary lectureship at Plymouth University. I am indebted particularly to colleagues at Plymouth for their interest and support in the initial development of this paper. I am also very grateful to the anonymous peer 
reviewers, and to Katherine Brickell, for detailed and insightful feedback that has significantly improved the quality of this paper.

\section{References}

Aitken, Stuart 2000. "Fathering and faltering: 'sorry but you don't have the necessary accoutrements'.” Environment and Planning A 32: 581-598. doi.org/10.1068/a3236

Balen, Rachel, Eric Blyth, Helen Calabretto, Claire Fraser, Christine Horrocks, and Martin Manby 2006. 'Involving Children in Health and Social Research: 'Human becomings' or 'active beings'." Childhood 13 (1): 29-38. doi.org/10.1177/0907568206059962

Barker, John 2011. “'Manic Mums' and 'Distant Dads'? Gendered geographies of care and the journey to school." Health and Place 17 (2): 413-421.

doi.org/10.1016/j.healthplace.2010.04.001

Bartholomew, Mitchell K., Sarah J. Schoppe-Sullivan, Michael Glassman, Claire M. Kamp Dush, Jason M. Sullivan. 2012. "New parents' Facebook use at the transition to parenthood." Family Relations 61 (3): 455-469. doi.org/10.1111/j.1741-3729.2012.00708.x

Bennett, Julia 2009. Vibrant matter: the political ecology of things. Duke University Press

Bennett, Julia 2015. "Snowed in! Offbeat rhythms and belongings as everyday practice." Sociology 49 (5): 955-969. doi.org/10.1177/0038038515589299

von Benzon, Nadia 2019a. "Unschooling and the simultaneous development and mitigation of 'otherness' amongst home-schooling families." Chapter 8 in Intersectionality and Difference in Childhood and Youth: Global Perspectives. Edited by von Benzon, Nadia and Catherine Wilkinson, Routledge, Abingdon

von Benzon, Nadia 2019b. "Informed consent and secondary data: Reflections on the use of mothers' blogs in social media research." Area 51(1): 182-189. doi.org/10.1111/area.12445

Boyer, Kate and Justin Spinney. 2015. "Motherhood, mobility and materiality: material entanglements, journey-making, and the process of 'becoming mother'." Environment and Planning D: Society and Space 34, 6, 1113-1131. doi.org/10.1177/0263775815622209

Carlsson, Hanna, Roos Pijpers and Vianne Melik. 2020. "Day-care centres for older migrants: spaces to translate practices in the care landscape." Social \& Cultural Geography, DOI: $\underline{\text { 10.1080/14649365.2020.1723135 }}$ 
Chae, Jiyoung 2017. "Explaining Females' Envy Toward Social Media Influences.” Media Psychology 21 (2): 246-262. doi.org/10.1080/15213269.2017.1328312

Choi, P., C. Henshaw, S. Baker and J. Tree. 2005. "Supermum, superwife, supereverything: performing femininity in the transition to motherhood." Journal of Reproductive and Infant Psychology 23 (2): 167-180. doi.org/10.1080/02646830500129487

Clement, Susannah and Gordon Waitt. 2017. "Walking, mothering and care: a sensory ethnography of journeying on-foot with children in Wollongong, Australia." Gender, Place \& Culture 24 (8): 1185-1203 doi.org/10.1080/0966369X.2017.1372376

Collom, Ed and Douglas Mitchell. 2005. "Home schooling as a social movement: Identifying the determinants of homeschoolers' perceptions." Sociological Spectrum 25 (3): 273-305. doi.org/10.1080/027321790518807

Conradson, David 2010. Geographies of Care: Spaces, practices, experiences. Social and Cultural Geography 4 (4): 451- 454. doi.org/10.1080/1464936032000137894

CRHE (2020), Homeschool Demographics, available at:

https://responsiblehomeschooling.org/homeschooling-101/homeschool-demographics/, accessed on: 29.01 .2020

Dahlen, Hannah, and Homer, Caroline S. (2013). 'Motherbirth or childbirth'? A prospective analysis of vaginal birth after caesarean blogs. Midwifery, 29(2), 167-173. 10.1016/j.midw.2011.11.007

Damaske, Sarah 2013. Work, Family and Accounts of Mothers' Lives Using Discourse to Navigate Intensive Mothering Ideals. Sociology Compass 7 (6): 436-444.

doi.org/10.1111/soc4.12043

Davies, Karen 2001. Responsibility and daily life: reflections over timespace. In: May, John and Thrift, Nigel (eds) Timespace: Geographies of temporality. London: Routledge, pp.133148.

Dawson, Mackenzie 2016 Parenting in a Fakebook World: How Social Media is Affecting Your Parenting, online, available at: www.parent.com/parenting/better-parenting/style/howsocial-media-is-affecting-your-parenting/

Dodd, Sandra 2009. The big book of unschooling. lulu.com.

Doty, Jennifer and Jodi Dworkin. 2013. "Parents' of adolescents use of social networking sites." Computers in Human Behavior, 33, 349-355. doi.org/10.1016/i.chb.2013.07.012 
Dyck, Isabel 1990. "Space, time, and renegotiating motherhood: an exploration of the domestic workplace." Environment and Planning D: Society and Space 8: 469-483. doi.org/10.1068/d080459

Edensor, Tim 2006. "Reconsidering national temporalities: insititional times, everyday routines, serial spaces and synchronicities." European Journal of Social Theory 9: 525-545. doi.org/10.1177/1368431006071996

Evans, Bethan 2009. "Anticipating Fatness: Childhood, affect and the pre-emptive 'war on obesity". Transactions of the Institute of British Geographers. 35 (1): 21-38. doi.org/10.1111/j.1475-5661.2009.00363.x

Frohlik, Susan 2006. "“Wanting the Children and Wanting K2': The incommensurability of motherhood and mountaineering in Britain and North America in the late twentieth century." Gender, Place \& Culture 13 (5): 477-490. doi.org/10.1080/09663690600858820

Gilmartin, Mary and Bettina Migge. 2016. "Migrant mothers and the geographies of belonging." Gender, Place \& Culture 23 (2): 147-161. doi.org/10.1080/0966369X.2014.991700

Gunthorpe, Wendy and Kevin Lyons. 2004 "A predictive model of chronic time pressure in the Australian population: Implications for leisure research." Leisure Sciences 26: 201-213. doi.org/10.1080/01490400490432127

Gray, Peter and Gina Riley. 2013. "The challenges and benefits of unschooling, according to 232 families who have chosen that route." Journal of Unschooling \& Alternative Learning 7 (14): 1-27. Online: https://jual.nipissingu.ca/wpcontent/uploads/sites/25/2014/06/v72141.pdf

Hagerstrand, Torsten 1985. "Time-geography: Focus on the corporeality of man, society, and environment", In: The Science and the praxis of complexity, Tokyo: The United Nations University, pp. 193-216.

Hall, Sarah M. and Clare Holdsworth. 2016. "Family practices, holiday and the everyday." Mobilities, 11: 284-302. doi.org/10.1080/17450101.2014.970374

Hinsliff, Gaby 2020. "As the lockdown bites, it's women who are taking the strain." The Guardian, online, available from:

https://www.theguardian.com/commentisfree/2020/apr/17/lockdown-women-working-motherscoronavirus-home-working, accessed 13.05.2020.

Holloway, Sarah L. and Helena Pimlott-Wilson. 2014. "Enriching Children, Institutionalizing Childhood? Geographies of Play, Extracurricular Activities, and Parenting in England." 
Annals of the Association of American Geographers 104 (3): 613- 627.

doi.org/10.1080/00045608.2013.846167

Holt, John 1976. Instead of Education: Ways to Help People Do Things Better. New York: EP Dutton.

Holt, Louise 2017. "Food, feeding and the material everyday geographies of infants: possibilities and potentials." Social and Cultural Geography. 18 (4): 487-504. doi.org/10.1080/14649365.2016.1193889

Holt, Louise, Sophie Bowlby, Jennifer Lea. 2013. "Emotions and the habitus: Young people with socio-emotional differences (re) producing social, emotional and cultural capital in family and leisure space-times." Emotion, Space and Society 9: 33- 41.

doi.org/10.1016/i.emospa.2013.02.002

Holton, Mark 2015. "Learning the rules of the 'student game': transforming the 'student habitus' through [im] mobility.” Environment and Planning A 47 (11): 2373-2388.

doi.org/10.1177/0308518X15599293

Horton, John 2018. "For the Love of Cuddly Toys." Children's Geographies 16(4): 446-454 doi.org/10.1080/14733285.2018.1457735

Jang, Juyoung and Jodi Dworkin,. 2014. "Does social network site use matter for mothers? Implications for belonging and bridging capital." Computers in Human Behavior 35: 489495. doi.org/10.1016/j.chb.2014.02.049

Johnson, Sophia A. 2015. “'Intimate mothering publics': comparing face-to-face support groups and internet use for women seeking information and advice in the transition to firsttime motherhood." Culture, Health and Sexuality 17 (2): 237- 251.

doi.org/10.1080/13691058.2014.968807

Jolly, Jennifer and Matthews, Michael 2017. "Why we blog: homeschooling mothers of gifted children.” Roeper Review 39 (2): 112- 120. doi.org/10.1080/02783193.2017.1289579

Kallio, Kirsi P. and Jouni Häkli. 2019. "Care as mundane politics: contested familial refugee lives in Finland." Gender, Place \& Culture 26(6): 795-812. doi.org/10.1080/0966369X.2018.1552563

Kendall, Lynne and Taylor, Elizabeth 2016. “'We can't make him fit into the system': parental reflections on the reasons why home education is the only option for their child who has special needs." Education 44 (3): 297-310. doi.org/10.1080/03004279.2014.974647 
Kraftl, Peter 2016. "Moments of Withdrawal: Homeschooling Mothers' Experiences of Taking Their Children Out of Mainstream Education." In Cameron, A., J.Dickson and N.Smith, eds. Body/State Routledge Abingdon. 157-172

Kraftl, Peter 2013. "Towards geographies of 'alternative' education: a case study of UK home schooling families." Transactions of the Institute of British Geographers. 38: 436450. doi.org/10.1111/j.1475-5661.2012.00536.x

Lefebvre, Henri 2004. Rythmanalysis: Space, Time and Everyday Life (Trans. S Elden and G Moore) New York: Athlone.

Lane, Rebecca 2014. "Healthy discretion? Breastfeeding and the mutual maintenance of motherhood and public space." Gender, Place \& Culture 21 (2): 195-210. doi.org/10.1080/0966369X.2013.791251

Lewis, Camilla 2017. "Turning houses into homes: Living through urban regeneration in East Manchester." Environment and Planning A. 49 (6): 1324-1340. doi.org/10.1177/0308518X17694360

Lewis, Helen, 2020. “The Coronavirus Is a Disaster for Feminism.” The Atlantic. Online, available from: https://www.theatlantic.com/international/archive/2020/03/feminism-womensrights-coronavirus-covid19/608302/, accessed: 13.05 .2020

Lloyd, Kathy, Wendy O'Brien, Caroline Riot. 2014. "Mothers with young children: Caring for the self through physical activity space." Leisure Science: An Interdisciplinary Journal. 38 (2): 85-99. doi.org/10.1080/01490400.2015.1076362

Lupton, Deborah 2013. "Infant embodiment and interembodiment: A review of sociocultural perspectives.” Childhood, 20, 1, 37-50. doi.org/10.1177/0907568212447244

Lupton, Deborah 2018. "How do data come to matter? Living and becoming with personal data." Big Data $\boldsymbol{\&}$ Society, 5(2), doi.2053951718786314.

Luzia, Karina 2010. "Travelling in your backyard: the unfamiliar places of parenting." Social and Cultural Geography. 11 (4): 359-375. doi.org/10.1080/14649361003774571

Mackay, Heather 2019. "A feminist geographic analysis of perceptions of food and health in Ugandan cities." Gender, Place \& Culture 26 (11): 1519-1543. doi.org/10.1080/0966369X.2018.1555148 
Madge, Clare 2007. 'Developing a geographers' agenda for online research ethics." Progress in Human Geography 31 (5): 654-674. doi.org/10.1177/0309132507081496

Madge, Clare and Henrietta O'Connor. 2006. "Parenting gone wired: empowerment of new mothers on the internet?" Social and Cultural Geography 7 (2): 199-220.

doi.org/10.1080/14649360600600528

Mailey, Emily L., Jennifer Huberty, Dannae Dinkel, and Edward McAuley. 2014. "Physical activity barriers and facilitators among working mothers and fathers." BMC Public Health, 14, 1. doi.org/10.1186/1471-2458-14-657

McDaniel, Brandon, Sarah Coyne, and Erin Holmes. 2012. "New Mothers and media use: Associations between blogging, social networking, and maternal well-being." Maternal and Child Health Journal. 16 (7): 1509-1517. doi.org/10.1007/s10995-011-0918-2

Medina, Jennifer and Lerer, Lisa, 2020. "When Mom's Zoom Meeting Is the One That Has to Wait." The New York Times. Online, available from:

https://www.nytimes.com/2020/04/22/us/politics/women-coronavirus-2020.html, accessed: 13.05. 2020.

Mee, Kathleen 2009. "A space to care, a space of care: public housing, belonging, and care in inner Newcastle, Australia.” Environment and Planning A, 41(4): 842-858.

doi.org/10.1068/a40197

Merleau-Ponty, Maurice 1968. The visible and the invisible. Trans. Alphonso Lingis. Evanston: Northwestern University Press.

Milligan, Christine, Mary Turner, Susan Blake et al. 2016. "Unpacking the impact of older adults' home death on family care-givers' experiences of home." Health and Place 38: 103111. doi.org/10.1016/i.healthplace.2016.01.005

Milligan, Christine 2000. “'Bearing the burden': Towards a restructured geography of caring." Area 32 (1): 49-58. doi.org/10.1111/j.1475-4762.2000.tb00114.x

Nockolds Danielle 2016. "Acceleration for working sole parents: squeezed between institutional temporalities and routinized parenting practices." Time and Society 25 (3): 513 532. doi.org/10.1177/0961463X15587838

O'Brien, Maeve 2007. "Mothers' emotional care work in education and its moral imperative." Gender and Education 19 (2): 159-177. do. org/10.1080/09540250601165938 
Oppenheim, Maya 2020. "Coronavirus broadening gender gap and aggravating existing inequality, report finds." The Independent, online, available from:

https://www.independent.co.uk/news/uk/home-news/coronavirus-uk-women-gender-gap-inequalitysex-a9497626.html, accessed 13.05.2020

Orton-Johnson, Kate 2017. "Mummy blogs and representations of motherhood:"Bad mummies" and their readers." Social Media and Society 3 (2):

doi.org/10.1177/2056305117707186

Parker, Brenda and Oona Morrow. 2017. "Urban homesteading and intensive mothering: (re) gendering care and environmental responsibility in Boston and Chicago." Gender, Place \& Culture 24 (2): 247-259 doi.org/10.1080/0966369X.2016.1277186

Parr, Hester and Chris Philo. 2003 "Rural mental health and social geographies of caring." Social and Cultural Geography 4 (4): 471-488. doi.org/10.1080/1464936032000137911

Parsons, Sarah and Ann Lewis. 2010. "The home-education of children with special needs or disabilities in the UK: views of parents from an online survey." International Journal of Inclusive Education 14 (1): 67-86. doi.org/10.1080/13603110802504135

Pedersen, Sarah 2014. Is it Friday yet? Mothers talking about sex online. Cyberpsychology: Journal of Psychological research on Cyberspace, 8, 2, 4 https://doi.org/10.5817/CP2014-2-4

Pederson, Sarah and Smithson, Janet 2013. "Mothers with attitude- How the Mumsnet parenting forum offers space for new forms of femininity to emerge online." Women's Studies International Forum. 97-106. doi.org/10.1016/j.wsif.2013.03.004

Petrovic, John and Rolstad, Kellie 2016. "Educating for autonomy: Reading Rousseau and Freire toward a philosophy of unschooling." Policy Futures in Education. online, 1-17. doi.org/10.1177/1478210316681204

Pimlott-Wilson, Helena 2011. "The role of familial habitus in shaping childen's views of their future employment." Children's Geographies 9 (1): 111-118.

doi.org/10.1080/14733285.2011.540443

Rose, Gillian 1993. Feminism and Geography: The limits of geographical knowledge. Mineapolis, US: Policy Press.

Rose, Judy, Brady, Michelle, Yerkes, Mara, and Coles, Laetitia. 2015. "'Sometimes they just want to cry for their mum': couples' negotiations and rationalisations of gendered division in infant care." Journal of Family Studies 21 (1): 38-56. doi.org/10.1080/13229400.2015.1010264 
Scharff, Xanthe, (2020), "Why the Coronavirus Outbreak could Hit Women Hardest." Time. online, available from https://time.com/5801897/women-affected-covid-19/, accessed on: 13.05.2020

Tahhan, Diana, 2013. "Teaching at Depth: The potential of feeling and connection." Emotion, Space and Society 7: 45-53. doi.org/10.1016/j.emospa.2012.03.004

Tarrant, Anna and Hall, Sarah M. 2019. "Everyday geographies of family: feminist approaches and interdisciplinary conversations." Gender, Place \& Culture, 1-11. doi.org/10.1080/0966369X.2019.1609430

Uprichard, Emma 2008. "Children as 'Being and Becomings': Children, Childhood and Temporality." Children and Society 22: 303-313. oi.org/10.1111/j.1099-0860.2007.00110.x

Whittle, Rebecca 2018. "Baby on Board: The Impact of sling use on experiences of family mobility with babies and young children." Mobilities. 14 (2): 137-157 doi.org/10.1080/17450101.2018.1533682

Wright, Sarah. 2015. "More-than-Human, Emergent Belongings: A Weak Theory Approach." Progress in Human Geography 39 (4): 391-411 doi.org/10.1177/0309132514537132 